\title{
The Antinociceptive Effect of Genicular Nerves Block Compared to Intra-Articular Dexamethasone in Grade III or IV Knee Osteoarthritis
}

\author{
Gabriela R. Lauretti ${ }^{1}$, Davi L. R. Santos ${ }^{2}$, Celia S. Oliveira ${ }^{3}$, Carlos Trintade $^{2}$
}

${ }^{1}$ Anesthesia and Pain Management, School of Medicine of Ribeirão Preto, University of São Paulo, São Paulo, Brazil; ${ }^{2}$ School of Medicine of RibeirãoPreto, University of São Paulo, São Paulo, Brazil; ${ }^{3}$ Interventional Pain, Teaching Hospital of the School of Medicine of RibeirãoPreto, University of São Paulo, São Paulo, Brazil

Correspondence to: Gabriela Rocha Lauretti, grlauret@fmrp.usp.br

Keywords: Blocking Genicular Nerves, Knee Pain, Knee Osteoarthritis

Received: August 29, 2019 Accepted: October 28, $2019 \quad$ Published: October 31, 2019

Copyright (c) 2019 by author(s) and Scientific Research Publishing Inc.

This work is licensed under the Creative Commons Attribution International License (CC BY 4.0).

http://creativecommons.org/licenses/by/4.0/

\section{(c) (i) Open Access}

\section{ABSTRACT}

Introduction: Knee pain secondary to osteoarthritis is a common pathology reflecting on the capacity of undertaking daily activities. Among non-surgical procedures, intra-articular corticosteroids represent an alternative complementary therapy. However, blocking the genicular nerves is a recently described technique, easily applied for clinical management. Objectives: To compare efficacy of both intra-articular corticosteroid and genicular block for chronic knee pain. Methods: 20 patients with osteoarthritis were evaluated for: 1) the intensity of pain; 2) the quality of sleep; 3 ) the capacity to undertake daily activities. Two groups were formed randomly, the first submitted to intra-articular blocking and the second to blocking the genicular nerves. A solution of plane $90 \mathrm{mg}$ lidocaine $1 \%$, and dexamethasone $10 \mathrm{mg}$ was standard and used for intervention in both procedures to a final $10-\mathrm{ml}$ volume. After a weekly appraisal for 12 consecutive weeks, the patients were recalled and submitted to another proposed procedure and in this way, all the patients acted as their own control (a "crossover" study design). In the following weeks, as also in the pretest, the intensity of pain, the quality of sleep and the capacity of undertaking daily activities were evaluated. Results: Both the intra-articular block and the genicular nerves block resulted equally in important reduction of pain during 11 weeks, with similar improvement in the quality of night sleep, and in the capacity of daily activities $(p<0.05)$. Conclusions: The blocking of the genicular nerves was a safe alternative, minimally invasive and highly efficient, similar to the intra-articular corticosteroid. 


\section{INTRODUCTION}

Osteoarthritis related knee pain is one of the most common musculoskeletal problems in elderly patients with an estimated prevalence of $24 \%[1,2]$. When conservative treatment has failed, different non-pharmacological and surgical treatment options are attempted. Intra-articular corticosteroid injection is one of the options suggested in the guidelines for the treatment of knee osteoarthritis [3, 4]. However, repetitive intra-articular corticosteroid injections have been reported to lead to various complications including deterioration of the articular cartilage, crystal-induced synovitis, fat necrosis, tissue atrophy, haematoma, vascular necrosis, and sepsis [5-9]. Recently, genicular nerve block has recently become a promising treatment option in the management of osteoarthritis related knee pain [10-12]. This procedure aims to provide pain relief by inhibiting the nerve fibers that innervate the knee joint. Nevertheless, there is no comparison between the efficacy of intra-articular block and genicular block of the knee. This study was designed to evaluate analgesia and quality of life in both procedures.

\section{METHODS}

A total of 20 patients with the diagnosis of knee osteoarthritis were included in the study during the years 2013-2017. The inclusion criteria were to have experienced dominant knee pain for more than 6 months, a diagnosis of radiologically verified grade III or IV osteoarthritis according to the Kellgren-Lawrence Grading Scale with prominent narrowing in the medial compartment of the tibiofemoral joint space. Exclusion criteria were determined as a history of knee surgery, experiencing acute knee pain with inflammation findings, connective tissue disease affecting the knee joint, a serious psychiatric disorder or neurological disease, sciatica, current use of anticoagulant drugs, and having received intra-articular steroid or hyaluronic acid injection within the previous 3 months. All participants signed the informed consent form. Approval for the study was granted by the Local Ethics Committee. The study was prospective, cross-matched. Ten patients started the study with genicular block, followed by intra-articular block after 12 -weeks. The other 10 patients were the reverse.

Genicular Nerve Block injections were performed under fluoroscopic guidance, in which needle placement was successfully applied with reference to bony landmarks (Figure 1 and Figure 2). The course of the superior medial genicular nerve (SMGN) is that it curves around the femur shaft and passes between the adductor magnus tendon and the femoral medial epicondyle, then descends approximately $1 \mathrm{~cm}$ anterior to the adductor tubercle. The inferior medial genicular nerve (IMGN) is situated horizontally

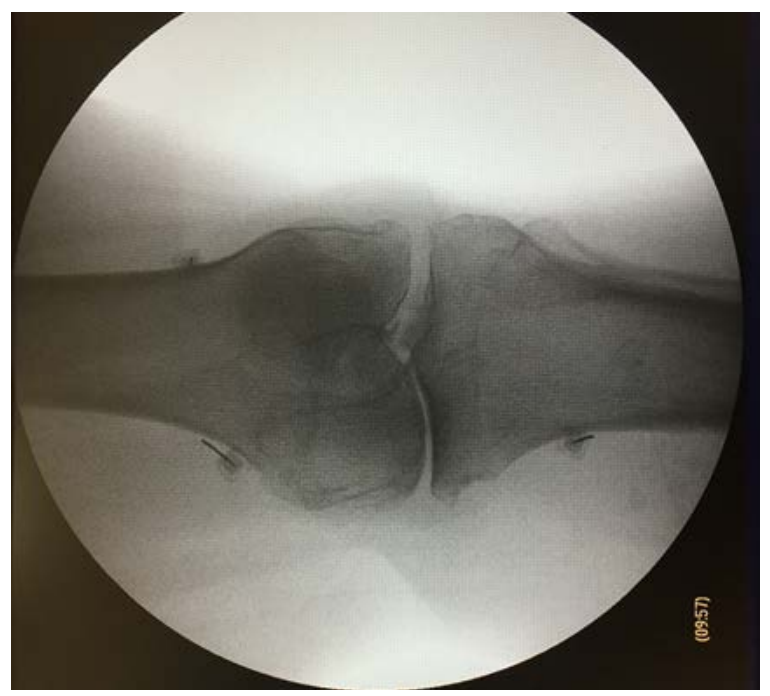

Figure 1. Genicular Nerve Block under fluoroscopic guidance, antero-posterior vision. 


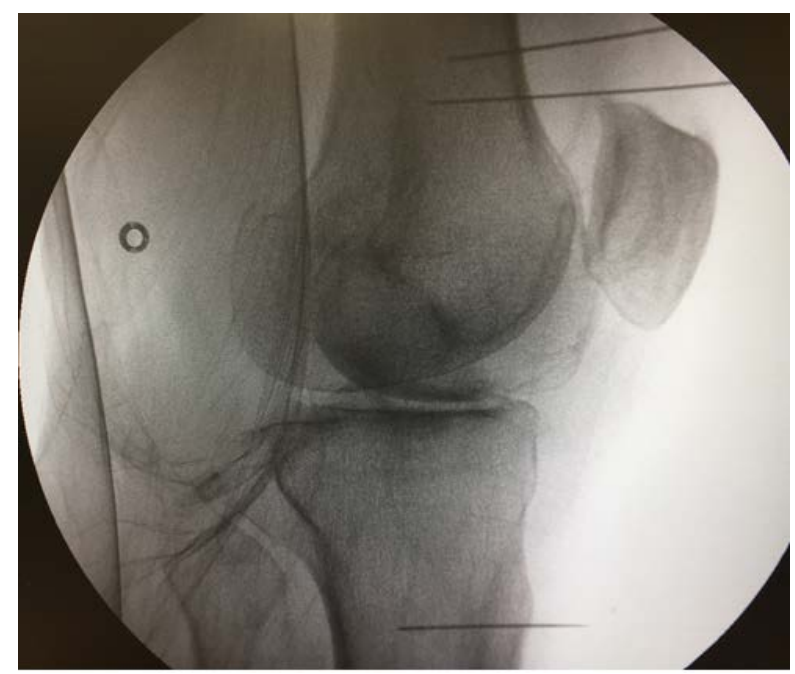

Figure 2. Genicular Nerve Block under fluoroscopic guidance, perfil vision.

around the tibial medial epicondyle and passes beneath the medial collateral ligament at the midpoint between the tibial medial epicondyle and the tibial insertion of the medial collateral ligament.

All patients were evaluated for: 1) the intensity of pain (Pain visual analog scale $0-10 \mathrm{~cm}$ ); 2) the quality of sleep (Numerical scale $0-10 \mathrm{~cm}) ; 3)$ [13] the capacity to undertake daily activities $(0-10 \mathrm{~cm})$. For all measures, zero meant no pain at all, or the best night sleep, or best performance of daily activities, varying to $10 \mathrm{~cm}$ (worse pain, worse night sleep and worse capacity for performing daily activities. Two groups were formed randomly, the first submitted to intra-articular blocking and the second to blocking the genicular nerves. Related to the quality of sleep, each patient acted as his/her own control, comparing the quality before and after the blocks. A solution of plane $90 \mathrm{mg}$ lidocaine 1\%, and dexamethasone $10 \mathrm{mg}$ was standard and used for intervention in both procedures to a final 10-ml volume. After a weekly appraisal for 12 consecutive weeks, the patients were recalled and submitted to another proposed procedure and in this way all the patients acted as their own control (a "crossover" study design). In the following weeks, as also in the pretest, the intensity of pain, the quality of sleep and the capacity of undertaking daily activities were evaluated.

The power of the study was based upon preliminary data. We hypothesised that the genicular block technique would increase time of analgesia by $70 \%$ compared to the intra-articular corticosteroid with a beta value of $80 \%$ and an alpha value of 0.05 , these assumptions would require at least 12 patients. $\mathrm{P}<0.05$ was considered significant. Data are expressed as means $\pm \mathrm{SD}$, unless otherwise stated.

The normality of the data was evaluated by the Shapiro Wilkings test. Demographic data was described. Quality of sleep, daily activities and analgesia time was evaluated by t-student (analgesia) or Wilcoxon Matched Pairs test (sleep and capacity). $\mathrm{P}<0.05$ was considered significant. Adverse effects were described.

\section{RESULTS}

The final data set included 16 subjects (total of 22 knees; 6 bilateral, 10 unilateral). Four of the patients did not get proper data collection and were excluded from the final evaluation.

Demographic data and routine oral drugs prescription are described in Table 1 and Table 2. All patients were taking daily combination of paracetamol and/or dipyrone prior to the interventional procedures $(\mathrm{p}>0.05)$.

The time of analgesia defined as time from the block until time when pain VAS $>3 \mathrm{~cm}$ is described in Table 3 ( $p>0.05)$. Both procedures resulted in 11 weeks of effective analgesia $(p>0.05)$. The sleep pattern 
Table 1. Demographics descritption.

\begin{tabular}{ccccc}
\hline & $\begin{array}{c}\text { Age } \\
\text { (age) }\end{array}$ & $\begin{array}{c}\text { Weight } \\
(\mathrm{Kg})\end{array}$ & $\begin{array}{c}\text { Height } \\
(\mathrm{cm})\end{array}$ & $\begin{array}{c}\text { Time of pain } \\
\text { (months) }\end{array}$ \\
\hline Mean & 65.18 & 71.81 & 166.25 & 8.93 \\
STD & 9.03 & 10.6 & 7.65 & 4.55 \\
\hline
\end{tabular}

STD-standard deviation.

Table 2. Demographics description.

\begin{tabular}{ccccc}
\hline & $\begin{array}{c}\text { Religion } \\
\text { (C ou E) }\end{array}$ & $\begin{array}{c}\text { Gender } \\
\text { M ou F }\end{array}$ & $\begin{array}{c}\text { Race } \\
\text { W ou B }\end{array}$ & Daily pain rescue analgesics \\
\hline \multirow{2}{*}{ Number } & C-13 & M-6 & W-11 & Dipyrone \\
& P-3 & F-10 & C-5 & Diclofenac \\
\hline
\end{tabular}

C-catholic, $\mathrm{P}=$ protestant; $\mathrm{M}$-male; F-female; $\mathrm{W}$-white, B-black.

Table 3. Time of adequate analgesia since the block until VAS $>3 \mathrm{~cm}$.

\begin{tabular}{ccc}
\hline & $\begin{array}{c}\text { TA- IA } \\
\text { (weeks) }\end{array}$ & $\begin{array}{c}\text { TA-Gen } \\
\text { (weeks) }\end{array}$ \\
\hline Mean & 10.87 & 11.31 \\
STD & 2.47 & 2.46 \\
\hline
\end{tabular}

STD-standard deviation, P > 0.05, IA-Intra-articular, Gen-Genicular block.

and the physical routine activities were quantified by patients using the VAS $(0-10 \mathrm{~cm})$ and were equally improved during controlled pain for both techniques, as quantified by the VAS scale by patients ( $\mathrm{p}>0.05)$. Related to the night sleep quality (Table 4), patients referred that when pain was under control, the night sleep was equally nice and comfortable for both groups (Table $3, p>0.05$ ), however uncomfortable during the periods of stronger pain with many times of arousal $(p<0.05)$. Similarly, the routine physical capacity was also equally improved for both treatments when pain was under control ( $p<0.05$ when compared to the uncontrolled pain period) (Table 5).

Related to adverse effects, all patients referred difficulty to sleep during the first night sleep when each block was performed, however, the day was not tiring, and all patients referred good disposition for activities $(\mathrm{p}>0.05)$.

\section{DISCUSSION}

Intra-articular corticoid has become widely used in the treatment of knee osteoarthritis [3]. However, sometimes, patient may not apply for it due to previous knee arthroplasty, previous knee infection, or even viscosupplementation failure. Surgical procedures are generally performed in cases unresponsive to the conservative treatment options, however, before performing the joint replacement, both intra-articular corticosteroid and genicular nerve blocks were demonstrated to be equally effective for pain control, resulting in 11 weeks of pain relief (VAS $<4 \mathrm{~cm}$ ), associated to a better night sleep pattern and a better performance of routine daily activities [10-12]. Genicular nerve ablation with radiofrequency has recently become a promising treatment option in the management of osteoarthritis related knee pain [10-12], 
Table 4. Night sleep pattern quality during the adequate periods of analgesia or without proper analgesia.

\begin{tabular}{cccc}
\hline & $\begin{array}{c}\text { Sleep pattern without } \\
\text { proper analgesia } \\
\text { (VAS } 0-10 \mathrm{~cm} \text { ) }\end{array}$ & $\begin{array}{c}\text { Sleep patter under IA } \\
\text { (VAS- }-10 \mathrm{~cm})\end{array}$ & $\begin{array}{c}\text { Sleep pattern under-Gen } \\
\text { (VAS- - }-10 \mathrm{~cm})\end{array}$ \\
\hline Mean & 6.025 & 3.13 & 3.25 \\
STD & 1.34 & 0.81 & 0.77 \\
\hline
\end{tabular}

IA-intraarticular, Gen-Genicular, STD-standard deviation, $\mathrm{P}<0.05$ (comparison between IA and Genblock prior to the study). VAS-Visual analog scale $0-10 \mathrm{~cm}$ (VAS $0-10 \mathrm{~cm}$, were zero means "best sleep pattern" until 10-cm which meant "worse sleep pattern").

Table 5. Capacity for routine daily activities during the adequate periods of analgesia or without proper analgesia.

\begin{tabular}{cccc}
\hline & $\begin{array}{c}\text { Capacity without } \\
\text { proper analgesia } \\
\text { (VAS } \mathbf{0}-\mathbf{1 0} \mathrm{cm})\end{array}$ & $\begin{array}{c}\text { Capacity under IA } \\
\text { (VAS } \mathbf{0}-\mathbf{1 0} \mathrm{cm})\end{array}$ & $\begin{array}{c}\text { Capacity under-Gen } \\
\text { (VAS 0 - 10 cm) }\end{array}$ \\
\hline Mean & 7.63 & 3.56 & 3.19 \\
STD & 1.15 & 0.89 & 0.63 \\
\hline
\end{tabular}

IA-intraarticular, Gen-Genicular, STD-standard deviation, $\mathrm{P}<0.05$ (comparison between IA and Genblock prior to the study). VAS-Visual analog scale $0-10 \mathrm{~cm}$ (VAS $0-10 \mathrm{~cm}$, were zero means "best routine daily activity" until $10-\mathrm{cm}$ which meant "worse routine daily activity").

however this as not the scope of the actual study. We were interested to compare the efficacy of the well demonstrated intra-articular corticosteroid compared to the recent described technique of genicular blocks at the knee.

The nerve supply of the knee joint is provided by various articular branches. It was described by 2 groups of articular branches in the knee: the anterior and posterior groups. The nerves in the anterior group are the articular branches of the femoral, the common peroneal and the saphenous nerve. The posterior group consists of the articular branches of the tibial, the obturator, and the sciatic nerves. The tibial nerve projects articular branches at the popliteal fossa and is mainly responsible for innervation of the medial and posterior aspect of the knee joint [14-16]. The articular branches of the common peroneal nerve innervate the inferolateral and anterolateral aspect of the articular capsule. The saphenous nerve gives sensation to the anteroinferior side of the capsule [14-16].

To our knowledge, this was the first randomized study to compare the analgesic efficacy of both procedures in patients radiologically verified grade III or IV osteoarthritis according to the Kellgren-Lawrence Grading Scale. We propose that because both technique resulted in similar efficacy, the intraarticular injection would block the same peripheral nerves terminals, compared to a more proximal block when the geniculate block was performed.

\section{DISCLAIMERS}

The views expressed in the submitted article are from the authors and not from the institution or funder. 


\section{RESEARCH FUNDING}

Sources were from the Brazilian government. There were no other grants or funding sources.

\section{CONFLICTS OF INTEREST}

There is no conflict of interest from any author.

\section{REFERENCES}

1. Pereira, D., Peleteiro, B., Araújo, J., Branco, J., Santos, R.A. and Ramos, E. (2011) The Effect of Osteoarthritis Definition on Prevalence and Incidence Estimates: A Systematic Review. Osteoarthritis Cartilage, 19, 1270-1285. https://doi.org/10.1016/j.joca.2011.08.009

2. Hunter, D.J., McDougall, J.J. and Keefe, F.J. (2008) The Symptoms of Osteoarthritis and the Genesis of Pain. Rheumatic Disease Clinics of North America, 34, 623-643.

3. de Campos, G.C., de Sousa, E.B., Hamdan, P.C., et al. (2019) Brazilian Consensus on Viscosupplementation of the Knee (COBRAVI). Acta Ortopédica Brasileira, 27, 230-236.

https://doi.org/10.1590/1413-785220192704218616

4. McDonough, A.L. (1982) Effects of Corticosteroids on Articular Cartilage. Physical Therapy, 62, 835-839. https://doi.org/10.1093/ptj/62.6.835

5. Noerdlinger, M.A. and Fadale, P.D. (2001) The Role of Injectable Corticosteroids in Orthopedics. Orthopedics, 24, 400-405.

6. Rozental, T.D. and Sculco, T.P. (2000) Intra-Articular Corticosteroids: An Updated Overview. The American Journal of Orthopedics, 29, 18-23.

7. Seror, P., Pluvinage, P., d'Andre, F.L., Benamou, P. and Attuil, G. (1999) Frequency of Sepsis after Local Corticosteroid Injection (an Inquiry on 1160000 Injections in Rheumatological Private Practice in France). Rheumatology, 38, 1272-1274. https://doi.org/10.1093/rheumatology/38.12.1272

8. Bellamy, N., Campbell, J., Welch, V., Gee, T.L., Bourne, R. and Wells, G.A. (2006) Intraarticular Corticosteroid for Treatment of Osteoarthritis of the Knee. Cochrane Database of Systematic Reviews, 2, CD005328. https://doi.org/10.1002/14651858.CD005328.pub2

9. Choi, W.J., Hwang, S.J., Song, J.G., Leem, J.G., Kang, Y.U., Park, P.H. and Shin, J.W. (2011) Radiofrequency Treatment Relieves Chronic Knee Osteoarthritis Pain: A Double-Blind Randomized Controlled Trial. Pain, 152, 481-487. https://doi.org/10.1016/j.pain.2010.09.029

10. Protzman, N.M., Gyi, J., Malhotra, A.D. and Kooch, J.E. (2014) Examining the Feasibility of Radiofrequency Treatment for Chronic Knee Pain after Total Knee Arthroplasty. $P M \& R, 6$, 373-376. https://doi.org/10.1016/j.pmrj.2013.10.003

11. Kesikburun, S., Yaşar, E., Uran, A., Adigüzel, E. and Yilmaz, B. (2016) Ultrasound-Guided Genicular Nerve Pulsed Radiofrequency Treatment for Painful Knee Osteoarthritis. A Preliminary Report. Pain Physician, 19, E751-E759.

12. Sutaria, R.G., Lee, S.W., Kim, S.Y., Howe, R. and Downie, S.A. (2017) Localization of the Lateral Retinacular Nerve for Diagnostic and Therapeutic Nerve Block for Lateral Knee Pain: A Cadaveric Study. $P M \& R, 9$, 149-153. https://doi.org/10.1016/j.pmrj.2016.06.017

13. Wickström, K. and Edelstam, G. (2017) Minimal Clinically Important Difference for Pain on the VAS Scale and the Relation to Quality of Life in Women with Endometriosis. Sexual \& Reproductive Healthcare, 13, 35-40. https://doi.org/10.1016/j.srhc.2017.05.004

14. Kennedy, J.C., Alexander, I.J. and Hayes, K.C. (1982) Nerve Supply of the Human Knee and Its Functional Im- 
portance. The American Journal of Sports Medicine, 10, 329-335. https://doi.org/10.1177/036354658201000601

15. Horner, G. and Dellon, A.L. (1994) Innervation of the Human Knee Joint and Implications for Surgery. Clinical Orthopaedics and Related Research, 301, 221-226. https://doi.org/10.1097/00003086-199404000-00034

16. Hirasawa, Y., Okajima, S., Ohta, M. and Tokioka, T. (2000) Nerve Distribution to the Human Knee Joint: Anatomical and Immunohistochemical Study. International Orthopaedics, 24, 1-4. https://doi.org/10.1007/s002640050001 